\title{
Electrochemical Oxidation Treatment of Wastewater Using Activated Carbon Electrode
}

\author{
Bo Yang ${ }^{1,2}$ and Jie Tang ${ }^{1, *}$ \\ ${ }^{1}$ College of Environment and Resources, Jilin University, Changchun 130000, China \\ ${ }^{2}$ Jilin Agricultural Science and Technology College School of Plant Science, Jilin 132011, China \\ *E-mail: tangjie0724@ sina.com
}

doi: $10.20964 / 2018.01 .78$

Received: 24 June 2017 / Accepted: 20 November 2017 / Published: 16 December 2017

\begin{abstract}
It has been widely accepted that wastewater contains low concentrations of organic pollutants and several inorganic salts after being biologically treated. This report presents a study of the synergic effects of electrosorption and electrochemical oxidation in the simultaneous removal of these substances. The electrochemical oxidization of phenol and sodium chloride occurred in the simulated wastewater in the presence of an anode made of activated carbon fibre (ACF) felt. We further studied the effect of anode structure and electrolytic conditions on the degradation of the wastewater. The removal of phenol was achieved by the synergic effect of electrochemical oxidation and adsorption, possibly maintained through the oxidization of hypochlorite and chlorine in either a direct or an indirect way. As degradation intermediates, chlorophenols were eventually converted into carboxylic acids. Desalination may be due to the ion electrosorption in the activated carbon electrode pores.
\end{abstract}

Keywords: Wastewater; Electrochemical oxidation; Activated carbon fibre; Water treatment; Environmental pollution

\section{FULL TEXT}

(C) 2018 The Authors. Published by ESG (www.electrochemsci.org). This article is an open access article distributed under the terms and conditions of the Creative Commons Attribution license (http://creativecommons.org/licenses/by/4.0/). 